\title{
Optimization of Millet Axial Flow Threshing and Separation Device Based on Discrete Element Method
}

\author{
Dongming ZHANG, Shujuan YI*, Haiyan LI, Jie GU, Fenfei ZHANG, Tao FENG
}

\begin{abstract}
The difficulties of threshing and separation of millet have not been solved yet which has restricted the development of the millet industry because of the special biological structure and lack of professional agricultural machinery. In order to improve the quality of millet harvest and meet the market demand for millet, in this paper, according to the branching structure of millet, the millet earhead model was established by Discrete Element Method. Using virtual models of millet and device, the simulation tests were carried out whose results have shown that the threshing effect of the rasp-bar threshing element is better than that of the teeth threshing element. Then the rotor structure was optimized into a combined type of the rasp-bar and the teeth. A three-factor five-level quadratic orthogonal rotation combination test was carried out whose results have shown that the combined rotor can meet the requirements of millet harvest.
\end{abstract}

Keywords: discrete element method; millet; simulation; threshing and separation

\section{INTRODUCTION}

Millet, the scientific name for Setaria italica, is an annual herbaceous plant belonging to the family Gramineae and Bristlegrass, which has the advantages of drought resistance, barren tolerance and good soil adaptability, etc. [1]. In China, millet is known as the head of coarse cereals planted widely up to about 100 thousand square kilometers, accounting for about 80 percent of the world's total output in the middle of the $20^{\text {th }}$ century [2]. The reason why millet production is rising after falling in recent years is that the millet market was greatly affected by rice and corn at first, but gradually it is believed that regular consumption of millet can effectively prevent many diseases, this led to its return to the market and its popularity $[3,4]$. Harvesting is one of the important links in millet production. However, the traditional harvesting machinery, which mainly focused on rice and corn, cannot achieve the harvest task of millet very well due to the special physiological structure of millet $[5,6]$. Therefore, it is of great significance to improve the level of millet harvesting mechanization by developing the matching machine tool [7].

Previous studies on the threshing and separation equipment have been carried out systematically. Miu \& Kutzbach (2008) presented a comprehensive and unitary stochastic mathematical model of grain threshing and separation in both axial and tangential threshing units. And the model was validated with data from a large database obtained from extensive testing of various axial and tangential threshing units. Fu Hong et al. (2012) used the particle polymer method to establish the analysis model of corn ear [8], and used the contact and connection mechanical model to calculate the force in the threshing process. Dai et al. (2016) used discrete element software EDEM to establish a particle model of threshing material (wheat grains, short stalks) in order to reduce the seed delay rate during the harvesting operation of the prototype [9], and simulated the movement and migration process of the threshing material in the cone-shaped threshing device and analyzed its characteristics. Zhang et al. (2020) designed a drum-shaped rod-tooth longitudinal axial flow threshing drum, and conducted simulation and experimental research on its power consumption [10]. The results showed that the drum-shaped threshing rotor has $5 \%$ to $15 \%$ lower power consumption than the cylindrical drum. Tian et al. (2020) optimized the working parameters of rape harvester, which could reduce the threshing loss rate to $0.47 \%$ [11].

To sum up, researchers have made some achievements in the study of threshing and separation device, mainly using mathematical theory and simulation method to optimize the structure of device, and then using experimental analysis to obtain the optimal combination of working parameters. Although there are few types of harvesters that can be used as a reference for crops with special structures such as millet, they have the same production process (stalk cutting, threshing, and cleaning) as that of rice and corn. The primary task of developing the millet industry is to change the structure of the working parts in response to the special biological structure of millet to achieve the goal of adapting to millet production. For the most widely used axial-flow threshing device, the quality of its work directly affects the harvest loss and the working environment of subsequent cleaning. Therefore, this paper used simulation and experimental verification methods to optimize the millet threshing and separation device. The millet model established by Discrete Element Method (DEM) was used for simulation experiment research which results were used in actual experiment to obtain the best parameter combination. It provides a theoretical basis for the optimization design of threshing components and optimization of threshing working parameters.

\section{MATERIALS AND METHOD}

\subsection{Structure Characteristics of Millet}

Millet consists of earheads, stalks and leaves, among which the structure of earhead is particular. The earhead composed of millet petal and grain, is located at the top of millet plant, and it is mostly cylindrical, whose length is 18 $-22 \mathrm{~cm}$. The millet petal composed of multi-level branches, spikelets and bristles, is mostly spherical in shape. The number of millet petals is between 80 and 120, and the diameter is between $8 \mathrm{~mm}$ and $15 \mathrm{~mm}$. The number of grains on each millet petal varies from 50 to 110 , according 
to its size. The structure of the millet plant is shown in Fig. 1.

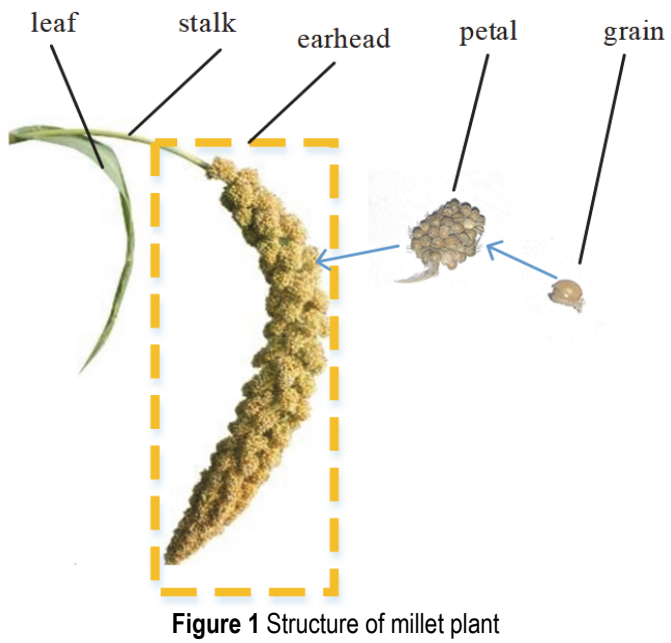

\subsection{Structure Characteristics of Millet Petals and Grains}

The primary branches of millet earheads are arranged in order on the circumference of the cob. There are secondary and tertiary branches growing on the primary branches, which are arranged in a disorderly manner so that the petal has different shapes. Each spikelet growing on the top of the tertiary branch has 1 to 3 serrated bristles. The tertiary branches, bristles, spikelet, and grains together form a minimum unit of a petal. The earhead branches are shown in Fig. 2.

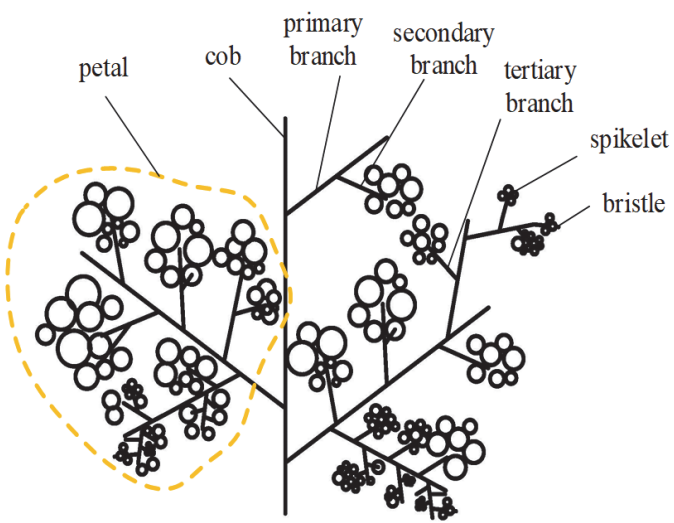

Figure 2 The structure of earhead branches

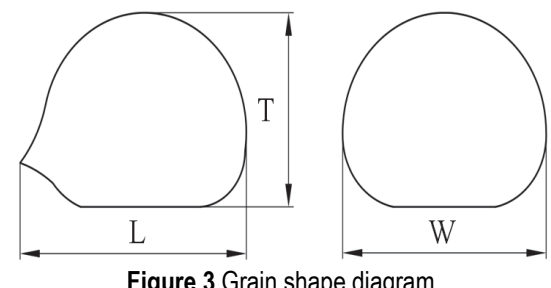

The size of millet grain is the smallest in cereal crops. Millet grain appearance is broadly rounded, and its surface is smooth and yellow. The triaxial size measurement of 100 millet grains was carried out, which results showed that the average length $(L)$, width $(W)$, and height $(T)$ of the millet grains were $1.56 \mathrm{~mm}, 1.52 \mathrm{~mm}$, and $1.47 \mathrm{~mm}$, respectively.

\subsection{Millet Earhead Model}

According to the above-mentioned millet structure data, discrete element method is used to model earhead. Considering the computational complexity of simulation and simplifying the simulation model, the grains and millet petals are regarded as spheres.

\subsubsection{Discrete Element Method and EDEM Software}

The discrete element method (DEM) is a valuable tool for investigating the microscopic properties of particles where transient forces and energy dissipation are difficult to obtain by conventional experimental techniques $[12,13]$. The method has been applied in agricultural research related to seed particles, such as rapeseed $[14,15]$. Moreover, it has been used to investigate a vertical mixer with regard to its dispersive and convective mixing mechanisms [16], and when coupled with computational fluid dynamics, it has been applied to investigate the effect of particle shape on the transportation mechanism in a well drilling [17]. It was also used to investigate a horizontal rotating tumbler with internal baffles and containing a mixture of two types of particles. The DEM was used to predict the internal load and moment distribution within rod-like particles and to examine the velocity, solid fraction, and particle-orientation fields of non-cohesive, spherocylindrical particles agitated in a vertical axis mixer for a range of particle aspect ratios and bed depths [18].

EDEM software was divided into three functional modules including Creator (This module is mainly used to complete the establishment of particle model, import of geometric model and parameter setting of particle system), Simulator (This module is used to solve the discrete element method of simulation calculation to simulate the movement process of the particle system) and Analyst (This module is used for data analysis and visualization of simulation results). The main functions of the software are shown in Fig. 4.

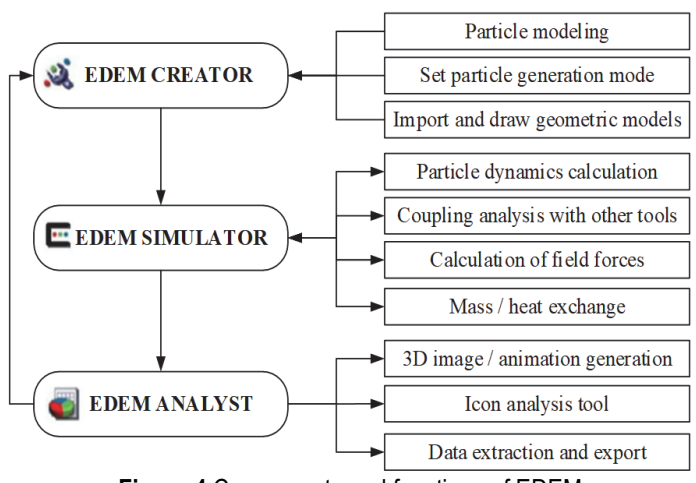

Figure 4 Components and functions of EDEM

\subsubsection{Simulation Contact Model}

It is necessary to establish the connection relationship between grains because of the special branching structure of the earheads. Therefore, the contact model of HertzMindlin with bonding which can produce bond between grains was selected. In this model, the contact algorithm is performed according to the contact model of HertzMindlin (no slip) to simulate the contact process of millet 
grains. When the distance between two particles is within the bonding radius, a bonding bond is formed between them. When the particle bears a normal or tangential force greater than the set critical value, the bonding bond disappears. This model simplifies tangential and normal contact forces into parallel connections of springs and dampers as shown in Fig. 5.

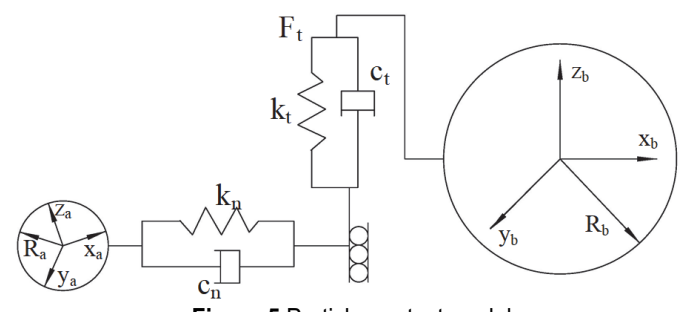

Figure 5 Particle-contact model

After the particles are bonded, the ratio of the normal force and moment of the particles $\left(F_{\mathrm{n}, t} / M_{\mathrm{n}, \mathrm{t}}\right)$ returns to zero, and the values of the normal force and moment are updated at each calculation time step by applying the following equation:

$$
\begin{aligned}
& \left\{\begin{array}{l}
\delta F_{\mathrm{n}}=-v_{\mathrm{n}} S_{\mathrm{n}} A \delta t \\
\delta F_{\mathrm{t}}=-v_{\mathrm{t}} S_{\mathrm{t}} A \delta t \\
\delta M_{\mathrm{n}}=-\omega_{\mathrm{n}} S_{\mathrm{t}} J \delta t \\
\delta M_{\mathrm{t}}=-\omega_{\mathrm{t}} S_{\mathrm{n}} \frac{J}{2} \delta t
\end{array}\right. \\
& A=\pi \cdot R_{\mathrm{B}}^{2}
\end{aligned}
$$

$$
J=\frac{1}{2} \cdot \pi \cdot R_{\mathrm{B}}^{4}
$$

where $A$ is contact area. $J$ is contact energy. $S_{\mathrm{n}}$ and $S_{\mathrm{t}}$ are normal and tangential stiffness, respectively. $R_{\mathrm{B}}$ is bond radius. $\delta_{\mathrm{t}}$ is time step. $v_{\mathrm{n}}$ and $v_{t}$ are normal and tangential velocities of particles, respectively. $\omega_{\mathrm{n}}$ and $\omega_{\mathrm{t}}$ are normal and tangential angular velocity, respectively.

Bond failure occurs when normal and tangential stresses exceed preset thresholds.

$$
\begin{gathered}
\sigma_{\max }<\frac{-F_{\mathrm{n}}}{A}+\frac{2 M_{\mathrm{t}}}{J} \cdot R_{\mathrm{B}} \\
\tau_{\max }<\frac{-F_{\mathrm{t}}}{A}+\frac{M_{\mathrm{n}}}{J} \cdot R_{\mathrm{B}}
\end{gathered}
$$

\subsubsection{Modeling Process of Millet Earhead}

The contact model of Hertz-Mindlin with bonding and the Application Programming Interface (API) of particle replacement are used to complete the modeling process. It includes three types of particles and two geometries. The three types of particles are millet grain sphere particles (The radius is $0.75 \mathrm{~mm}$ ), millet petal sphere particles (The radius is $4 \mathrm{~mm}$ ), and particles $L$ (The radius not less than $100 \mathrm{~mm}$ ), in which particles L can wrap the whole earhead to ensure that it can be replaced. The two geometries are earhead contour model (The radius of the cylinder is 11 $\mathrm{mm}$ and the height is $200 \mathrm{~mm}$ ) and the upper and lower hemisphere model of petal (The radius is $4 \mathrm{~mm}$ ). The modeling process of millet earhead is shown in Fig. 6 .

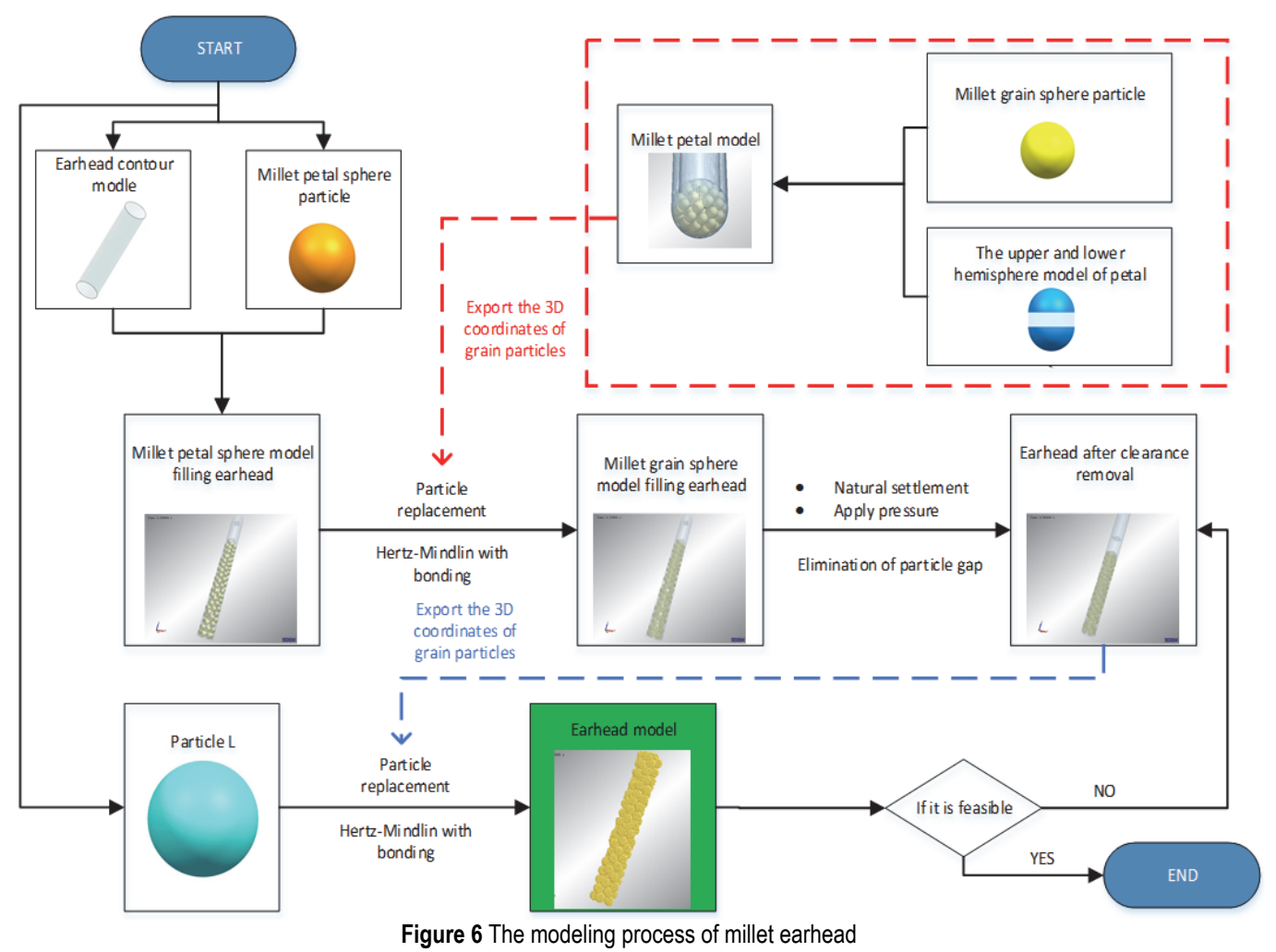

\subsection{Threshing and Separation Device Model}

The threshing and separation device model refers to the structure of the combine harvester produced by Xingguang agricultural machinery manufacturer. Its main parts include threshing rotor, concave, upper cover, etc. Its 
main components include threshing rotor, concave, upper cover and so on, in which the threshing rotor contains two common types (rasp-bar type and teeth type), and the gridtype concave was picked. Three-dimensional modeling of two types of the rotor is shown in Fig. 7.

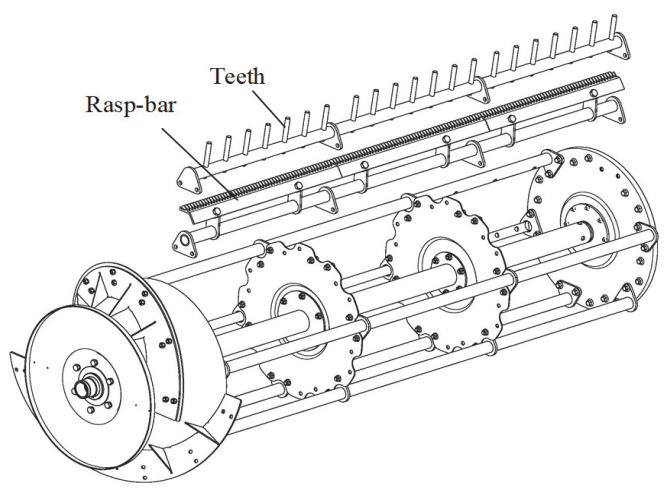

Figure 7 The 3D model of two types of rotor

\section{RESULTS AND DISCUSSION \\ 3.1 Simulation Process}

Firstly, the model of each component of the device was imported into EDEM 2.7.0. In addition, a receiving device is introduced under the threshing and separation device to facilitate the statistics of particles data. The contact model of Hertz-Mindlin with bonding and API of create particles, which can make particles be created according to the coordinates at the beginning of the simulation, and the movement of conveyor belt model were used to realize the feeding of earheads. About 50 earheads were fed into the device in each process as shown in Fig. 8. The contact parameters of each material are shown in Tab. 1. Before they entered the device, the speed of the threshing rotor must be defined. When earheads entered the device, under the action of the threshing element, the bonds between particles were broken, causing particles separation, and finally falling into the receiving device. The simulation process is shown in Fig. 9.

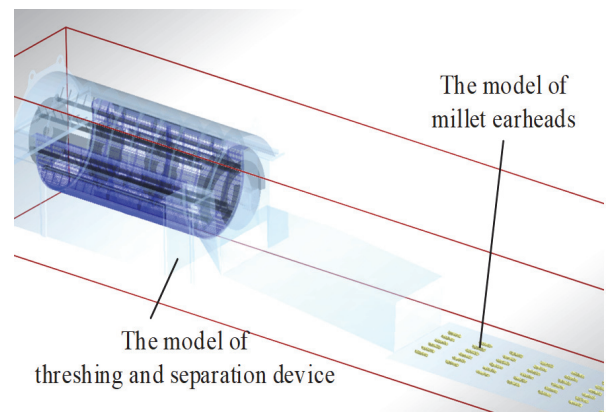

Figure 8 Earheads formation

Table 1 Simulated contact coefficients

\begin{tabular}{|l|c|c|c|c|}
\hline \multicolumn{1}{|c|}{$\begin{array}{c}\text { Contact } \\
\text { coefficients }\end{array}$} & $\begin{array}{c}\text { Static } \\
\text { friction }\end{array}$ & $\begin{array}{c}\text { Rolling } \\
\text { Friction }\end{array}$ & $\begin{array}{c}\text { Sliding } \\
\text { friction }\end{array}$ & Restitution \\
\hline Grain-grain & 0.32 & 0.02 & 0.38 & 0.33 \\
\hline Grain-geometry & 0.35 & 0.02 & 0.38 & 0.39 \\
\hline
\end{tabular}

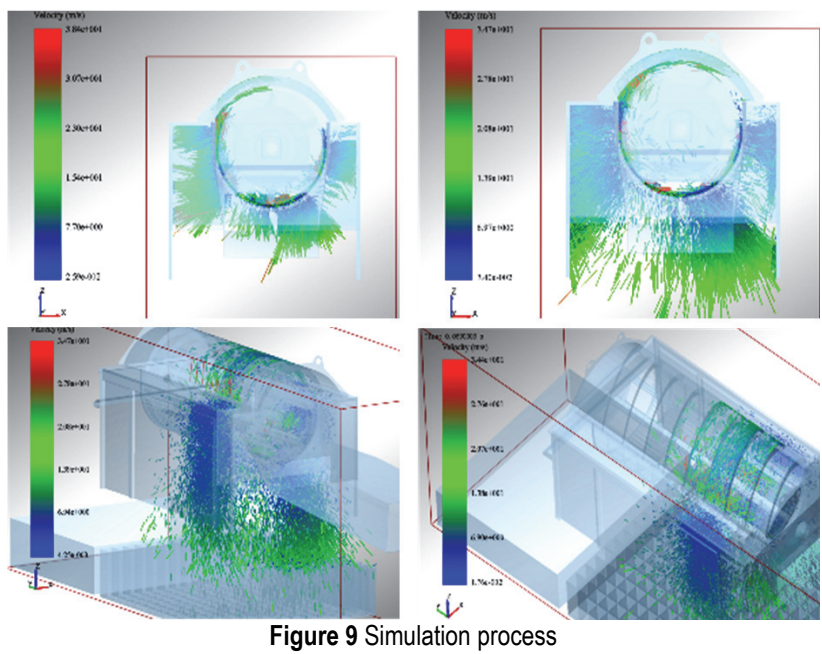

3.2 Simulation Experimental Index

Experimental indicators included millet petals rate, loss rate and miscellaneous rate. The millet petals rate $G_{\mathrm{f}}$ is the number of intact bond $n_{\mathrm{s}}$ to the number of generated bond $n_{\mathrm{z}}$. The loss rate $S_{\mathrm{f}}$ is the number of millet particles discharged from the outlet $N_{\mathrm{p}}$ to the number of total grain particles $N_{\mathrm{t}}$. The miscellaneous rate $Z_{\mathrm{f}}$ is the number of stalk particles falling into the receiving device $n_{1}$ to the number of total stalk particles $n_{\mathrm{t}}$. The calculation formulas are as follow.

$G_{\mathrm{f}}=\frac{n_{\mathrm{s}}}{n_{\mathrm{z}}} \times 100 \%$

$S_{\mathrm{f}}=\frac{N_{\mathrm{p}}}{N_{\mathrm{t}}} \times 100 \%$

$Z_{\mathrm{f}}=\frac{n_{1}}{n_{\mathrm{t}}} \times 100 \%$

\subsection{Simulation Experimental Method and Results 3.3.1 Comparative Test of Rotor Types}

A comparative test of two types of rotors was carried out under the condition of $800 \mathrm{r} / \mathrm{min}$ rotating speed of the rotor, concave grid size $32 \times 6 \mathrm{~mm}, 2 \mathrm{~kg} / \mathrm{s}$ feeding amount, $8 \mathrm{~mm}$ threshing clearance. The result is shown in Tab. 1, The histogram of test results is shown in Fig. 10.

Table 1 Rotor speed test results
\begin{tabular}{|l|l|c|c|c|}
\hline & \multicolumn{1}{|c|}{ Rotor form } & $\begin{array}{c}\text { Millet petals rate } \\
/ \%\end{array}$ & $\begin{array}{c}\text { Loss rate } \\
/ \%\end{array}$ & $\begin{array}{c}\text { Miscellaneous } \\
\text { Rate } / \%\end{array}$ \\
\hline 1 & Rasp-bar type & 7.81 & 1.61 & 22.74 \\
\hline 2 & Teeth type & 14.55 & 1.48 & 15.38 \\
\hline
\end{tabular}

It can be concluded that the loss rate of threshing is almost the same for the two types of rotor by analyzing the results of the comparative test. However, the millet petals rate of threshing with the rotor of rasp-bar type was lower than that with teeth type, while the miscellaneous rate was higher than that with teeth type. The reason is that the raspbar type rotor which has a large area of action and mainly works by squeezing only has less ability to transfer kinetic energy to particles. This caused the stalk particles stay in 
the threshing space for a long time, which increases the possibility of falling into the hopper through the concave grid, resulting in the increase of miscellaneous rate. The teeth type rotor mainly works by striking and its effective area of threshing element is far less than that of rasp-bar type causing the increase of millet petals rate. Furthermore, the greater kinetic energy transmitted by the blow makes it easier for stalk particles to be discharged from the outlet resulting in the reduction of the miscellaneous rate.
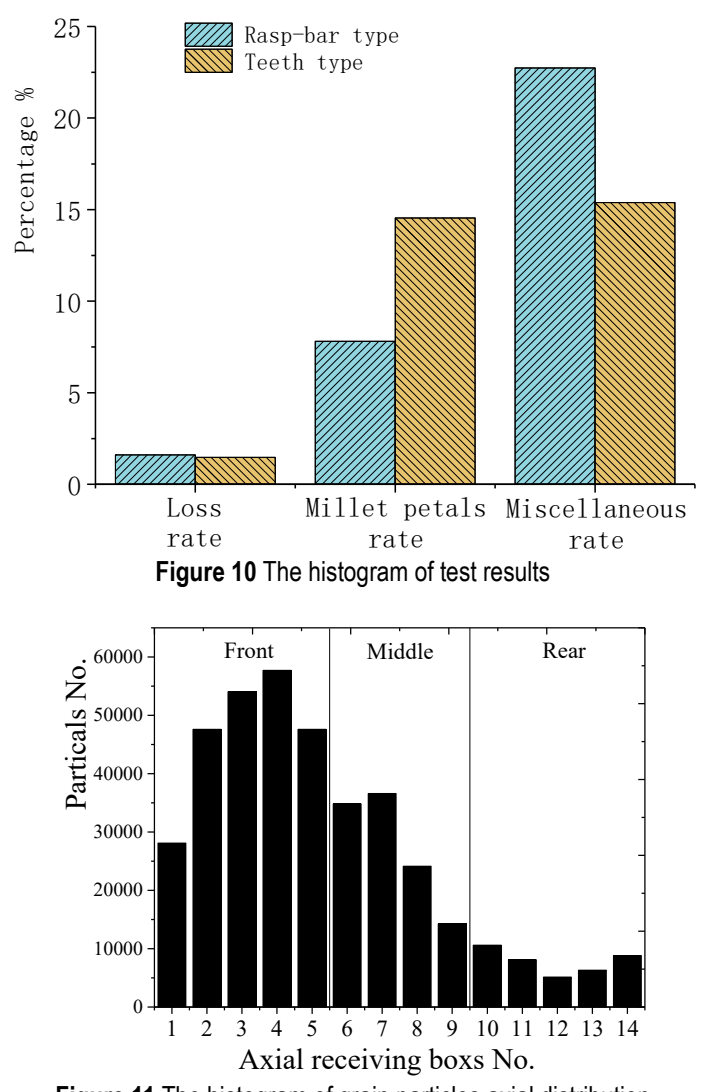

Figure 11 The histogram of grain particles axial distribution

According to the analysis of the results, the rasp-bar rotor is more suitable for the threshing of millet, so a further analysis was made on the distribution of the grains in rasp-bar type. The axial distribution of millet grain particles in the simulation test is shown in Fig. 11. It can be seen from the image that the millet grains are mainly distributed in the front and middle section, and the rear grains are significantly reduced, indicating that the millet threshing has almost been completed in the front and middle section of the rotor. The use of the rasp-bar pattern increases the action time of the stalk particles, which is not conducive to grass row.

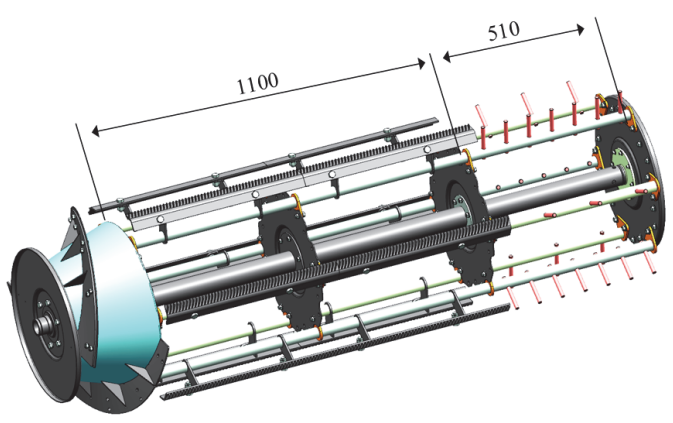

Figure 12 The combined rotor
On the contrary, the use of teeth rotor to speed up the discharge of stalk is conducive to the continuity of the whole threshing process, and also improves the threshing quality. To sum up, the rotor was optimized to be a combination type so that the front part was rasp-bar and the rear part was teeth. The length of the front part was 1100 $\mathrm{mm}$, and the rear part was $510 \mathrm{~mm}$. The three-dimensional diagram of the combined rotor is shown in Fig. 12.

\subsubsection{Single Factor Test Simulation and Analysis}

The simulation experiment shown in Tab. 2 was carried out by changing the rotating speed of the rotor under the condition of the combined rotor, feeding amount $2 \mathrm{~kg} / \mathrm{s}$, threshing clearance $8 \mathrm{~mm}$ and concave grid size 32 $\times 6 \mathrm{~mm}$. The curve corresponding to the simulation test results is shown in Fig. 13.

Table 2 Simulation test results of rotor speed

\begin{tabular}{|c|c|c|c|c|}
\hline & $\begin{array}{c}\text { Rotor speed / } \\
\text { r/min }\end{array}$ & $\begin{array}{c}\text { Millet petals } \\
\text { rate / } \%\end{array}$ & $\begin{array}{c}\text { Loss rate } \\
/ \%\end{array}$ & $\begin{array}{c}\text { Miscellaneous } \\
\text { rate / \% }\end{array}$ \\
\hline 1 & 500 & 8.88 & 1.05 & 32.17 \\
\hline 2 & 600 & 8.24 & 1.22 & 27.66 \\
\hline 3 & 700 & 7.9 & 1.29 & 22.13 \\
\hline 4 & 800 & 7.52 & 1.33 & 17.79 \\
\hline 5 & 900 & 7.1 & 2.1 & 19.12 \\
\hline 6 & 1000 & 6.56 & 3.25 & 20.07 \\
\hline 7 & 1100 & 6.06 & 3.93 & 22.91 \\
\hline 8 & 1200 & 5.85 & 5.01 & 25.48 \\
\hline
\end{tabular}

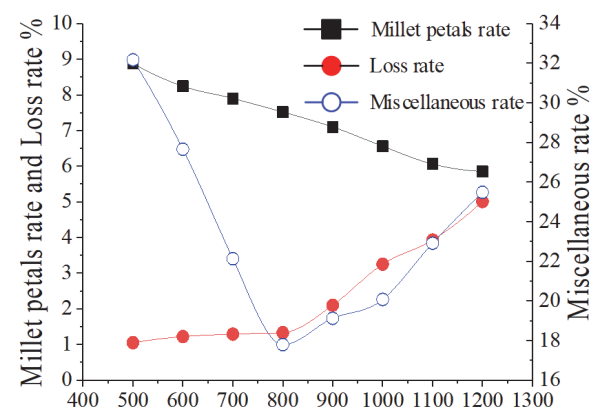

Speed of rotor ( $\mathrm{r} / \mathrm{min})$

Figure 13 Curve of simulation test of rotor speed

The simulation test results of rotor speed were analyzed as follows: With the increase of rotor speed, the loss rate is gradually increasing. When the rotor speed reached $900 \mathrm{r} / \mathrm{min}$ and continued to increase, the slope of loss rate increased. When the rotor speed was $1200 \mathrm{r} / \mathrm{min}$, the loss rate was the highest, which was $5.01 \%$. The reason was that the kinetic energy of millet particles was large after the rotor speed increased, and the interaction force between particles in the simulation environment was less than that in the actual operation, so the grains with large kinetic energy were easy to be discharged from the outside of the device through the axial stalk outlet, causing losses. With the increase of rotor speed, the miscellaneous rate first decreased and then increased. When the rotor speed was $800 \mathrm{r} / \mathrm{min}$, the miscellaneous rate reached the lowest, which was $17.79 \%$. When the rotor speed was $500-800$ $\mathrm{r} / \mathrm{min}$, the miscellaneous rate decreased greatly. The reason was that when the rotation speed was low, the kinetic energy of the stalks produced by the threshing element was minor. The stalk particles spent a long-term in the device and moved in a spiral axial direction under the action of the guide plate, which increased the possibility of stalk 
particles passing through the concave grid.

The simulation experiment shown in Tab. 3 was carried out by changing the spacing of strips of the concave under the condition of the combined rotor, rotating speed of the rotor $800 \mathrm{r} / \mathrm{min}$, feeding amount $2 \mathrm{~kg} / \mathrm{s}$ and threshing clearance $8 \mathrm{~mm}$. The curve corresponding to the simulation test results is shown in Fig. 14.

Table 3 Simulation test results of spacing of strips

\begin{tabular}{|c|c|c|c|c|}
\hline & $\begin{array}{c}\text { Spacing of } \\
\text { strips } / \mathrm{mm}\end{array}$ & $\begin{array}{c}\text { Millet petals } \\
\text { rate } / \%\end{array}$ & $\begin{array}{c}\text { Loss rate } \\
/ \%\end{array}$ & $\begin{array}{c}\text { Miscellaneous } \\
\text { rate } / \%\end{array}$ \\
\hline 1 & 3 & 5.49 & 3.54 & 11.52 \\
\hline 2 & 4 & 5.86 & 2.92 & 11.60 \\
\hline 3 & 5 & 6.34 & 1.81 & 15.32 \\
\hline 4 & 6 & 7.52 & 1.33 & 17.79 \\
\hline 5 & 7 & 8.17 & 1.25 & 22.71 \\
\hline 6 & 8 & 9.58 & 1.16 & 26.83 \\
\hline 7 & 9 & 9.62 & 1.09 & 27.84 \\
\hline 8 & 10 & 9.53 & 0.99 & 27.90 \\
\hline 9 & 11 & 10.21 & 0.98 & 27.84 \\
\hline 10 & 12 & 10.57 & 0.94 & 28.22 \\
\hline
\end{tabular}

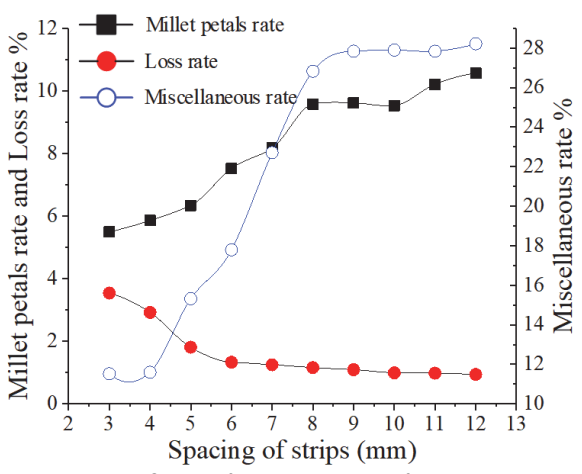

Figure14 Curve of simulation test of rotor speed

The simulation test results of spacing of strips were analyzed as follows: With the increase of grid screen spacing, the overall loss rate showed a downward trend. When the screen spacing was between $6 \mathrm{~mm}$ and $8 \mathrm{~mm}$, the change of loss rate tended to be flat. The reason was that when the spacing between the sieve strips was small, the grains of millet were not easy to fall into the receiving device through the concave grid, but spiral with the axial movement of the drum, and finally discharged from the stalk outlet, resulting in losses. With the increase of the grid spacing, the miscellaneous rate showed an upward trend. The reason is that when the grid size was large, the stalk particles were easy to pass through the grid and fall into the receiving device.

\subsection{Multi-Factor Test}

The selected tying experiment factors included speed of rotor, threshing clearance and spacing of strips. Their variation ranges were reasonably controlled. The factor level codes are shown in Tab. 4.

Table 4 Levels of experimental factors

\begin{tabular}{|c|c|c|c|}
\hline \multirow[b]{2}{*}{ Levels } & \multicolumn{3}{|c|}{ Factors } \\
\hline & $\begin{array}{c}\text { Speed of rotor } \\
x_{1} / \mathrm{r} / \mathrm{min}\end{array}$ & $\begin{array}{c}\text { Threshing clearance } \\
x_{2} / \mathrm{kg} / \mathrm{s}\end{array}$ & $\begin{array}{c}\text { Spacing of strips } \\
x_{3} / \mathrm{mm}\end{array}$ \\
\hline$r$ & 1000 & 12 & 12 \\
\hline 1 & 920 & 10 & 10 \\
\hline 0 & 800 & 8 & 8 \\
\hline-1 & 680 & 6 & 6 \\
\hline$-r$ & 600 & 4 & 4 \\
\hline$\Delta_{j}$ & $118.91 \approx 120$ & $2.38 \approx 2$ & $2.38 \approx 2$ \\
\hline
\end{tabular}

The three-factor five-level orthogonal rotation combination design method was selected in the experiment scheme. Clean threshing rate, millet petals rate, and loss rate were selected as the experiment indexes. 23 groups of experiments were conducted, and each group of experiment was repeated 3 times. The experiment results were averaged. The experiment scheme and experiment results are shown in Tab. 5.

Table 5 Test scheme and results

\begin{tabular}{|c|c|c|c|c|c|c|}
\hline \multirow{2}{*}{$\begin{array}{c}\text { Test } \\
\text { No. }\end{array}$} & \multicolumn{2}{|c|}{ Implementation plan } & $\begin{array}{c}\text { Clean } \\
\text { threshing rate } \\
x_{1} / \%\end{array}$ & $\begin{array}{c}\text { Millet } \\
\text { petals rate } \\
y_{2} / \%\end{array}$ & $\begin{array}{c}\text { Loss rate } \\
y_{3} / \%\end{array}$ \\
\hline 1 & 680 & 6 & 6 & 82.75 & 15.52 & 1.73 \\
\hline 2 & 920 & 6 & 6 & 87.62 & 11.21 & 1.17 \\
\hline 3 & 680 & 10 & 6 & 74.79 & 21.03 & 4.18 \\
\hline 4 & 920 & 10 & 6 & 80.06 & 16.55 & 3.39 \\
\hline 5 & 680 & 6 & 10 & 76.05 & 20.62 & 3.33 \\
\hline 6 & 920 & 6 & 10 & 83.81 & 14.21 & 1.98 \\
\hline 7 & 680 & 10 & 10 & 76.01 & 18.71 & 5.28 \\
\hline 8 & 920 & 10 & 10 & 81.33 & 16.36 & 2.31 \\
\hline 9 & 600 & 8 & 8 & 78.58 & 16.94 & 4.48 \\
\hline 10 & 1000 & 8 & 8 & 87.23 & 11.48 & 1.29 \\
\hline 11 & 800 & 4 & 8 & 86.12 & 12.54 & 1.34 \\
\hline 12 & 800 & 12 & 8 & 76.62 & 19.37 & 4.01 \\
\hline 13 & 800 & 8 & 4 & 83.47 & 15.36 & 1.17 \\
\hline 14 & 800 & 8 & 12 & 77.93 & 19.23 & 2.84 \\
\hline 15 & 800 & 8 & 8 & 89.81 & 9.45 & 0.74 \\
\hline 16 & 800 & 8 & 8 & 89.97 & 9.52 & 0.51 \\
\hline 17 & 800 & 8 & 8 & 88.26 & 11.19 & 0.55 \\
\hline 18 & 800 & 8 & 8 & 90.13 & 8.64 & 1.23 \\
\hline 19 & 800 & 8 & 8 & 88.90 & 10.00 & 1.10 \\
\hline 20 & 800 & 8 & 8 & 89.67 & 9.40 & 0.93 \\
\hline 21 & 800 & 8 & 8 & 88.01 & 11.19 & 0.80 \\
\hline 22 & 800 & 8 & 8 & 89.94 & 8.79 & 1.27 \\
\hline 23 & 800 & 8 & 8 & 90.57 & 8.57 & 0.86 \\
\hline & & & & & & \\
\hline
\end{tabular}

In order to obtain the best parameter combination for millet harvesting, the regression equations of clean threshing rate, millet petals rate, and loss rate were optimized and analyzed using Design-Expert 8.0.6 software. The regression equations were optimized and solved using the comprehensive objective function method to establish a mathematical model. Comprehensively considering the conditions and scope of experiment factors of each index, a nonlinear programming mathematical model was obtained:

$$
\left\{\begin{array}{l}
\max y_{1} \\
\min y_{2} \\
\min y_{3} \\
\text { s.t. } 600 \mathrm{r} / \mathrm{min} \leq x_{1} \leq 1000 \mathrm{r} / \mathrm{min} \\
4 \mathrm{~mm} \leq x_{2} \leq 12 \mathrm{~mm} \\
4 \mathrm{~mm} \leq x_{3} \leq 12 \mathrm{~mm} \\
0 \leq y_{1}\left(x_{1}, x_{2}, x_{3}\right) \leq 1 \\
0 \leq y_{2}\left(x_{1}, x_{2}, x_{3}\right) \leq 1 \\
0 \leq y_{3}\left(x_{1}, x_{2}, x_{3}\right) \leq 1
\end{array}\right.
$$

Comprehensive objective function solution was carried out to the quadratic regression equations using Design-Expert 8.0.6 software. When the clean threshing rate was maximum, the millet petals rate and the loss rate were minimum. The best parameter scheme under the comprehensive objective function was as follows: the 
speed of rotor was $864.91 \mathrm{~mm}$, the threshing clearance was $7.03 \mathrm{~mm}$, and the spacing of strips was $7.41 \mathrm{~mm}$. The performance indexes obtained under the best parameters were as follows: the clean threshing rate was $91.01 \%$, the millet petals rate was $8.62 \%$, and the loss rate was $0.37 \%$.

\subsection{Test Verification}

A verification experiment was performed according to the optimal parameter combination of the quadratic regression equations. The speed of rotor was rounded to $865 \mathrm{r} / \mathrm{min}$, the threshing clearance was rounded to $7 \mathrm{~mm}$, and considering the manufacturing process, the spacing of strips was rounded to $8 \mathrm{~mm}$. The experiment was repeated 3 times and the experiment results were averaged. The experiment-verified performance index result obtained under the best parameters was as follows: the clean threshing rate was $90.65 \%$, the millet petals rate was $8.74 \%$, and the loss rate was $0.61 \%$. The verification experiment results are similar to the software optimization result and the error rate is $\leq 5 \%$. The experimental results can meet the technical requirements of millet production.

\section{CONCLUSIONS}

(1) The composition and branching structure of millet earheads were analyzed and the simulation model was established by using the contact model of Hertz-Mindlin with bonding, and the application-programming interface of particle replacement and particles creation.

(2) The simulation test was carried out. According to the analysis of the simulation index and the distribution of the threshing process, the threshing rotor is optimized to be the combination of rasp-bar and teeth, which is more suitable for millet threshing.

(3) The fitted regression equations were optimized and solved using the comprehensive objective function method and Design-Expert 8.0.6 software. The optimum combination of threshing parameters was obtained and the verification test was carried out under the optimized parameters. The verification test results were as follows: when the rotor speed was $865 \mathrm{r} / \mathrm{min}$, the threshing clearance was $7 \mathrm{~mm}$, and the spacing of strips was $8 \mathrm{~mm}$. The experiment-verified performance indexes: the clean threshing rate was $90.65 \%$, the millet petals rate $8.74 \%$, and the loss rate $0.61 \%$, which achieved the requirements of millet harvest.

\section{Acknowledgments}

This work was supported by the National Key Research and Development Program (China), Study on Mechanical Characteristics of Mechanical Harvesting and Separation of Coarse Crops (Grant No. 2016YFD070180103), and Research and Development of Self-propelled Millet Combine Harvester (Grant No. 2016YFD0701803), and Research and Development of Crawler Millet Combine Harvester (Grant No. 2016YFD0701803-02).

\section{REFERENCES}

[1] Song, H., Li, J., Wang, S., Yan, H., Xie, M., Song, Z., Zhang, Y., \& Gong, B. (2015). Regional Distribution and
Development of Millet in China. Journal of Anhui Agricultural, 43(20), 330-332.

[2] Liu, J., Wang, X., Wu, Y., Jia, H., Yi, X., Shi, L., Chu, Q., \& Chen, F. (2019). Spatiotemporal Variation and Regional Advantages of Foxtail Millet Production in Recent 30 Years in China. ScientiaAgriculturaSinica, 52(11), 1883-1894. https://doi.org/10.1016/j.cclet.2019.08.041

[3] Li, S., Zhao, Y., Liu, F., Xia, X., Nan, C., \& Liu, M. (2018). Elements change and mechanization level of foxtail millet production. Chinese Agricultural Science Bulletin, 34(10), 153-158.

[4] Wu, Q. (2019). Latest development trend of foreign combine harvesters. Tractor \& Farm Transporter, 46(4), 1-10.

[5] Li, Y., Guo, E., Fan, H., Wang, L., Zhang, A., Liu, X., \& Cheng, L. (2019). Discussion on development of millet industry. Modern Agricultural Science and Technology, 22, 28-29.

[6] Ji, J., Li, X., Jin, X., Geng, L., He, Z., Li, S., \& Pang, J. (2016). Present situation, technical analysis and equipment demand of harvesting mechanization for characteristic coarse cereals. Agricultural Engineering, 6(6), 1-3.

[7] Cui, Y., Qin, Y., Wang, H., Jiao, Z., Wang, L., Han, K., \& Ni, G. (2020). Discussion on mechanized harvesting technology of millet. Agricultural Machinery, 1,108-110.

[8] Fu, H., Lv, Y., Li, Y., \& Yu, J. (2012). Analysis for corn threshing process based DEM. Agricultural Machinery Journal of Jilin University (Engineering and Technology Edition), 42(4), 997-1002.

[9] Dai, F., Zhao, W., Han, Z., Li, X., Gao, A., \& Liu, X. (2016). Improvement and Experiment on 4GX-100 Type Wheat Harvester for Breeding Plots. Transactions of the Chinese Society for Agricultural Machinery, 47(S1), 196-202.

[10] Zhang, G., Xie, G., Fu, J., Zhou, Y., Wang, Y., Gao, Y., \& Wang, W. (2020). Comparing power consumption of drum and cylindrical rod-tooth longitudinal axial flow threshing roller. Journal of Huazhong Agricultural University, 1-8.

[11] Tian, W., Ma, L., Zong, W., \& Wei, J. (2020). Effects of operating parameters of rapeseed axial flow threshing device on loss rate and dust production concentration. Journal of Anhui Agricultural University, 47(6),1038-1044.

[12] Moreno-Atanasio, R. (2012). Energy dissipation in agglomerates during normal impact. Powder Technology, 223, 12-18. https://doi.org/10.1016/j.powtec.2011.05.016

[13] Zhu, H., Zhou, Z., Yang, R., \& Yu, A. (2008). Discrete particle simulation of particulate systems: A review of major applications and findings. Chemical Engineering Science, 63(23), 5728-5770. https://doi.org/10.1016/j.ces.2008.08.006

[14] Coetzee, C. J. \& Els, D. N. J. (2009). Calibration of discrete element parameters and the modelling of silo discharge and bucket filling. Computers and Electronics in Agriculture, 65(2), 198-212. https://doi.org/10.1016/j.compag.2008.10.002

[15] Wiacek, J. \& Molenda, M. (2011). Moisture-dependent physical properties of rapeseed-experimental and DEM modeling. International Agrophysics, 25(1), 59-65.

[16] Schmelzle, S., Leppert, S., \& Nirschl, H. (2015). Influence of impeller geometry in a vertical mixer described by DEM simulation and the dispersion model. Advanced Powder Technology, 26(5), 1473-1482. https://doi.org/10.1016/j.apt.2015.08.003

[17] Akhshik, S., Behzad, M., \& Rajabi, M. (2016). CFD-DEM simulation of the hole cleaning process in a deviated well drilling: The effects of particle shape. Particuology, 25, 7282. https://doi.org/10.1016/j.partic.2015.02.008

[18] Hua, X., Curtis, J., Guo, Y., Hancock, B., Ketterhagen, W., \& Wassgren, C. (2015). The internal loads, moments, and stresses in rod-like particles in a low-speed: vertical axis mixer. Chemical Engineering Science, 134, 581-598. https://doi.org/10.1016/j.ces.2015.06.001 


\section{Contact information:}

\section{Dongming ZHANG}

College of Engineering,

Heilongjiang Bayi Agricultural University,

Daqing 163319, Heilongjiang, China

Shujuan YI

(Corresponding author)

College of Engineering,

Heilongjiang Bayi Agricultural University,

Daqing 163319, Heilongjiang, China

E-mail: yishujuan_2005@126.com

\section{Haiyan LI}

Heilongjiang Agricultural Radio and Television School,

(Hailun branch campus), Hailun 152300, China

\section{Jie GU}

Huzhou Fengyuan Agricultural Equipment Manufacturing Co., Ltd,

Huzhou 313000, Zhejiang, China

\section{Fenfei ZHANG}

Xingguang Agricultural Machinery Co., Ltd,

Huzhou 313000, Zhejiang, China

\section{Tao FENG}

Xingguang Agricultural Machinery Co., Ltd,

Huzhou 313000, Zhejiang, China 